\title{
Non-Destructive Testing in Complexes Cabling Networks using Time Domain Reflectometry and Particle Swarm Optimization
}

\author{
Hamza Boudjefdjouf \\ Université de Constantine 1 \\ laboratoire d'Electrotechnique de \\ Constantine 25000 \\ Algerie \\ hamza.boudjefdjouf@lec-umc.org
}

\author{
Rabia Mehasni, Houssem \\ Bouchekara \\ Université de Constantine 1 \\ laboratoire d'Electrotechnique de \\ Constantine 25000, Algerie \\ mehasni@yahoo.fr \\ bouchekara.houssem@gmail.com
}

\author{
Antonio orlandi, Francesco De paulis \\ UAq EMC Laboratory, Dept of \\ Industrial and Information Engineering \\ and Economics, via G. Gronchi, 18, \\ 67100 - L'AQUILA - ITALY \\ antonio.orlandi@ing.univaq.it \\ francesco.depaulis@univaq.it
}

\begin{abstract}
Non-Destructive Testing (NDT) is an important area of research, dealing with diagnostic and monitoring the health of the electrical transmission networks and find automatically the failures. One of the recently developped (NDT) techniques is Time Domain Reflectometry methods, they are quite efficient for detecting important damages (hard faults), such as short or open-circuits.

Interpreting the results obtained with reflectometry instrument for a wiring network requires great expertise, as the reflectometry response can be very complex. Morever, the reflectometry response it self is not self-sufficient to identify and localate the defects in cabling networks. There is the need to solve efficiently the inverse problem which consists of deducing some knowledge about the defects from the response at the input point of the network.

In this paper, TDR and PSO algorithm have been combined and applied to produce a new sufficiently optimized method that permit the extaraction of damages informations from the time domain reflectograms. Finite Difference Time Domain (FDTD) method has been used to produce a training data set with the known of damages. The results obtained from the TDR-PSO algorithm confirmed the theoretical predictions, and gave us exact informations about the complexe structure's health.
\end{abstract}

\section{INTRODUCTION}

$\mathrm{T}$ $\mathrm{DR}$ is a measurement technique used to determine the characteristics of electrical lines by observing reflected waveforms [1]. The impedance of the discontinuity can be determined from the amplitude of the reflected signal. The distance to the reflecting impedance can also be determined from the time that a pulse takes to return.

Due to the complex characteristics of the cabling networks which mean that the TDR responses are not self-explanatory some papers use different techniques to read and explain those responses [2] [3] [4].

In this paper a forward model is developed to generate TDR responses and the particle swarm optimization (PSO) technique is used to solve the inverse problem in order to detect and localize faults.

This paper is organized as follows. The proposed TDRPSO approach is presented in section 2. In section 3, the results are exposed and discussed. Finally, conclusions are drawn in section 4 .

\section{The Proposed TDR-PSO ApproACh}

The Finite Difference Time Domain (FDTD) method is employed as the forward model to generate the TDR responses based on an input Gaussian pulse. The construction of the forward response is based on the knowledge of the healthy network, such as the network topology thus the number and location of the junctions, the characteristic impedance of the lines, and the length of each line section etc... Moreover the assumption that all the final network branches are terminated on an open load. A basic assumption is that the response simulated by the FDTD algorithm is consistent to the measured response for the healthy network case. This assumption must be verified anytime a new network needs to be analyzed then; the PSO is applied to the inverse process after the generated TDR response using the forward model is compared with the measured one. If a fault is present along the network then the measured TDR response would not match to the simulated response of the healthy network, thus the PSO algorithm operates to modify the topology of a faulty network. This process is repeated until the termination criterion (convergence) is achieved.

\section{A. The forward model}

The scalar transmission-line equations for two-conductor lines are:

$\frac{\partial V(z, t)}{\partial z}=-R \cdot I(z, t)-L \cdot \frac{\partial I(z, t)}{\partial t}$

$\frac{\partial I(z, t)}{\partial z}=-G V(z, t)-C \cdot \frac{\partial V(z, t)}{\partial t}$ 
Where $\mathrm{V}$ and $\mathrm{I}$ are $n \times 1$ vectors of the line voltages and line currents, respectively. The position along the line is denoted as $z$ and time is denoted as $t$. The $\mathrm{R}$ (resistance), $\mathrm{L}$ (inductance), $\mathrm{C}$ (capacitance) and $\mathrm{G}$ (conductance) are the per-unit-length parameters. The values of these parameters are computed analytically.

$Z_{c}=\sqrt{\frac{L}{C}}$

As an alternative method of obtaining this general solution we have used the FDTD method which converts the differential equations into recursive finite difference equations [5].

Replacing the derivatives with centered differences in (1) and (2), we obtain the following recurrence equations:

$\left[\frac{\mathrm{L}}{\Delta \mathrm{t}}+\frac{\mathrm{R}}{2}\right] \mathrm{I}_{\mathrm{k}}^{\mathrm{n}+1}=\left[\frac{\mathrm{L}}{\Delta \mathrm{t}}-\frac{\mathrm{R}}{2}\right] \mathrm{I}_{\mathrm{k}}^{\mathrm{n}}-\frac{\mathrm{L}}{\Delta \mathrm{z}}\left[\mathrm{V}_{\mathrm{k}+1}^{\mathrm{n}}-\mathrm{V}_{\mathrm{k}}^{\mathrm{n}}\right]$
$\left[\frac{\mathrm{C}}{\Delta \mathrm{t}}+\frac{\mathrm{G}}{2}\right] \mathrm{V}_{\mathrm{k}}^{\mathrm{n}+1}=\left[\frac{\mathrm{C}}{\Delta \mathrm{t}}-\frac{\mathrm{G}}{2}\right] \mathrm{V}_{\mathrm{k}}^{\mathrm{n}}-\frac{1}{\Delta \mathrm{z}}\left(\mathrm{I}_{\mathrm{k}}^{\mathrm{n}-1}-\mathrm{I}_{\mathrm{k}-1}^{\mathrm{n}-1}\right)$

\section{B. Characteristic impedance and measurement of the coaxial} cable:

In this work, the RG58 CU coaxial cable shown in Figure 1 has been used. For this coaxial cable the capacitance per unit length, $\mathrm{C}$, and inductance per unit length, L, are functions of cable geometry [6].

The per-unit length parameters of this coaxial cable are :

$$
\begin{gathered}
C=\frac{2 \pi \varepsilon}{\ln \left(\frac{R_{i}}{A}\right)}=100 \times 10^{-12} \mathrm{~F} / \mathrm{m} \\
L=\frac{\frac{\mu}{2 \pi}}{\ln \left(\frac{R_{i}}{A}\right)}=250 \times 10^{-9} \mathrm{H} / \mathrm{m} \\
G=C w \cdot \operatorname{tg}(\delta)=2 w \times 10^{-13} \mathrm{~S} / \mathrm{m} \\
r=\left(1 / \pi A^{2} \sigma\right)+\left(1 / \sigma \pi\left(R_{0}+R_{i}\right)\left(R_{0}-R_{i}\right)\right) \\
=0.02 \Omega / \mathrm{m}
\end{gathered}
$$

Where $A, R_{i}$ and $R_{0}$ are the radii of the inner outer and external conductors; $\mu$ and $\varepsilon$ are the magnetic permeability and dielectric permittivity, respectively, of the material between the conductors, $\operatorname{tg}(\delta)$ is the dissipation factor.

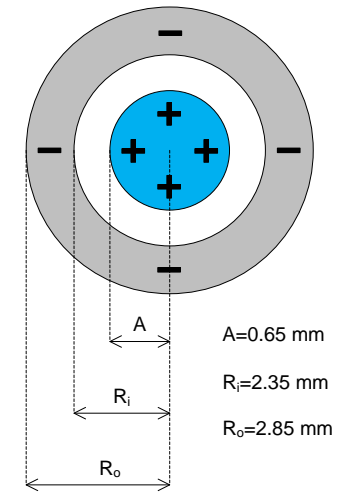

Figure 1: RG 58 CU coaxial cable.

\section{Time Domain Reflectometry Measurements}

The classical way to do TDR measurements is to inject a signal into the inner conductor of the coaxial cable, which propagates along the cable and when meeting a discontinuity of impedance, a part of its energy is reflected back to the injection point where it is then measured. This reflectogram is used to detect, localize and characterize defects.

A vector network analyzer (VNA Anritsu $10 \mathrm{MHz}-2 \mathrm{GHz}$ ) has been used to inject the signal into the inner conductor of the RG 58 coaxial cable and to measure the response. The impulse response is deduced from measurement of $S_{11}$ parameter in the frequency domain from $10 \mathrm{MHz}$ to $2 \mathrm{GHz}$ and by using IFFT (Inverse Fast Fourier Transform) to move from frequency to the time domain. A raised cosine pulse, with a rising time of $4 \mathrm{~ns}$ and amplitude of $1 \mathrm{~V}$ has been used.

\section{Solving the Inverse Problem Using the Particle} Swarm Optimization

\section{D.1 overview}

PSO [7] is an evolutionary algorithm for the solution of optimization problems. It belongs to the field of Swarm Intelligence and Collective Intelligence and is a sub-field of Computational Intelligence. It was developed by Eberhart and Kennedy [7] and inspired by social behavior of bird flocking or fish schooling. Several modifications in the PSO algorithm had been done by various researchers [8]. PSO is simple in concept, as it has a few parameters only to be adjusted. It has found applications in various areas like constrained optimization problems, min-max problems, multi-objective optimization problems and many more [8].

The PSO [9] method is regarded as a population-based method, where the population is referred to as a swarm. The swarm consists of $n$ individuals called particles, each of which represents a candidate solution [10]. Each particle $i$ in the swarm holds the following information: (i) it occupies the position $x_{\mathrm{i}}$, (ii) it moves with a velocity $v_{\mathrm{i}}$, (iii) the best position, the one associated with the best fitness value the particle has achieved so far pbest $t_{\mathrm{i}}$, and (iv) the global best 
position, the one associated with the best fitness value found among all of the particles gbest.

The fitness of a particle is determined from its position. The fitness is defined in such a way that a particle closer to the solution has higher fitness value than a particle that is far away. In each iteration, velocities and positions of all particles are updated to persuade them to achieve better fitness. The process of updating is repeated iteratively either until a particle reaches the global solution within permissible tolerance limits, or until a sufficiently large number of iterations is reached. Magnitude and direction of movement of a particle is influenced by its previous velocity, its experience and the knowledge it acquires from the swarm through social interaction.

\section{D.2 Velocity and position of the particles}

In every iteration, each particle adjusts its own trajectory in the space in order to move towards its best position and the global best according to the following equations:

$$
\begin{aligned}
& v_{i j}^{t+1}=w v_{i j}^{t}+c_{1} \operatorname{rand}_{1 j}^{t}\left(\text { pbest }_{i j}^{t}-x_{i j}^{t}\right)+ \\
& c_{2} \operatorname{rand}_{2 j}^{t}\left(\text { gbest }_{j}^{t}-x_{i j}^{t}\right) \\
& x_{i j}^{t+1}=x_{i j}^{t}+v_{i j}^{t+1}
\end{aligned}
$$

for $j \in 1 . . d$ where $d$ is the number of dimensions, $i \in 1 . . n$ where $n$ is the number of particles, $t$ is the iteration number, $w$ is the inertia weight, rand $_{1}$ and rand $_{2}$ are two random numbers uniformly distributed in the range [0,1], and $c_{1}$ and $c_{2}$ the acceleration factors. $c_{1}$ is the cognitive acceleration constant. This component propels the particle towards the position where it had the highest fitness. $c_{2}$ is the social acceleration constant. This component steers the particle towards the particle that currently has the highest fitness.

The velocity of a particle is bounded between properly chosen limits $v_{\min }<v_{\text {id }}<v_{\max }$ (in most cases $v_{\min }=-v_{\max }$ ). Similarly, the position of a particle is restricted between properly chosen constants $x_{\min }<x_{\mathrm{id}}<x_{\max }$.

Afterwards, each particle updates its personal best using the equation (assuming a minimization problem):

$$
\text { pbest }_{i}^{t+1}= \begin{cases}\text { pbest }_{i}^{t} & \text { if } f\left(\text { pbest }_{i}^{t}\right) \leq f\left(x_{i}^{t+1}\right) \\ x_{i}^{t+1} & \text { if } f\left(\text { pbest }_{i}^{t}\right)>f\left(x_{i}^{t+1}\right)\end{cases}
$$

Finally, the global best of the swarm is updated using the equation (assuming a minimization problem):

$$
\text { gbest }^{t+1}=\arg \min f\left(\text { pbest }_{i}^{t+1}\right)
$$

Where $f$, is a function that evaluates the fitness value for a given position.

The general Particle swarm optimization method is described in algorithm 1.
Algorithm 1 Particle Swarm Optimization
1: $\{$ Initialization $\}$
2: for $\mathrm{i}=1$ to $\mathrm{n}$ do

3: initialization of position and velocity of each particle

4: $\mathrm{p}_{\mathrm{i}}=\mathrm{x}_{\mathrm{i}}$

5: $\mathrm{p}_{\text {besti }}=\infty$

6: end for

7: while termination condition not true do

8: $\quad$ for $\mathrm{i}=1$ to $\mathrm{n}$ do

9: $\{$ Update personal best positions $\}$

10: $\quad$ if $f\left(x_{i}\right)<p_{\text {besti }}$ then

11: $\quad \mathrm{p}_{\mathrm{i}}=\mathrm{x}_{\mathrm{i}}$

12: $\quad p_{\text {besti }}=\mathrm{f}\left(\mathrm{x}_{\mathrm{i}}\right)$

13: end if

14: $\{$ Update global best particle $\}$

15: if $f\left(p_{\text {besti }}\right)<g_{\text {besti }}$ then

16: $\mathrm{g}_{\text {besti }}=\mathrm{p}_{\text {besti }}$

17: $\quad$ end if

18: end for

19: $\{$ Update velocities and positions $\}$

20: for $\mathrm{i}=1$ to $\mathrm{n}$ do

21: $v_{i j}^{t+1}=w v_{i j}^{t}+c_{1} \operatorname{rand}_{1 j}^{t}\left(\right.$ pbest $\left._{i j}^{t}-x_{i j}^{t}\right)+$ $c_{2} \operatorname{rand}_{2 j}^{t}\left(\right.$ gbest $\left._{j}^{t}-x_{i j}^{t}\right)$

22: $x_{i j}^{t+1}=x_{i j}^{t}+v_{i j}^{t+1}$

23: end for

(44i:) end while

\section{APPLICATIONS AND RESULTS}

In order to illustrate the proposed methodology two complexes networks configurations are investigated which are: the YY and the YYY-shaped networks. For each configuration three cases are studied: the healthy network, a network with one fault and a network affected with more than one fault.

Our objective, knowing the topology of the network, is to detect, localize and characterize these faults through finding the length $\left(L_{\mathrm{i}}\right)$ and the resistance $\left(R_{\mathrm{i}}\right)$ of each branch. The location of each assumed fault is characterized by two parameters: the index of its branch and its distance from the input while the characterization can be either a short circuit or an open circuit.

It worth mentioning that all the TDR responses represented in this article are plotted as a function of distance from the test (or origin) point in order to facilitate relating the main peaks with the configuration of the network.

\section{A. The $Y Y$-shaped network}

Figure 2 shows the experimental network composed of five branches $L_{1}=1 \mathrm{~m}, L_{2}=4 \mathrm{~m}, L_{3}=1 \mathrm{~m}, L_{4}=0.5 \mathrm{~m}$ and $L_{5}=1.5 \mathrm{~m}$ respectively. 


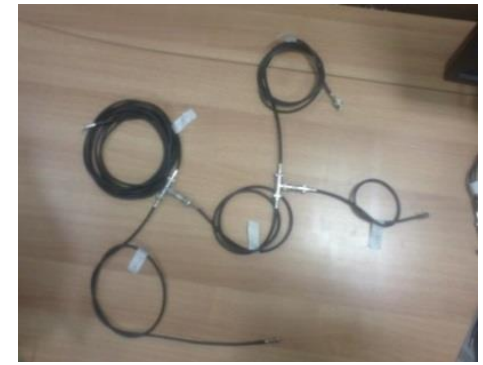

Figure 2: The YY-shaped network.

Before starting the fault study of the second configuration, the healthy network is investigated. The TDR responses obtained using measurements and simulations are sketched in figure 3. The analysis of the measured and the simulated TDR presented in figure 3 shows that the positions and amplitudes of the main peaks correspond to the topology of the tested network. Moreover, this figure shows that there is a good matching between the measured and simulated results. The small differences are due to the fact that the skin effect has been neglected.

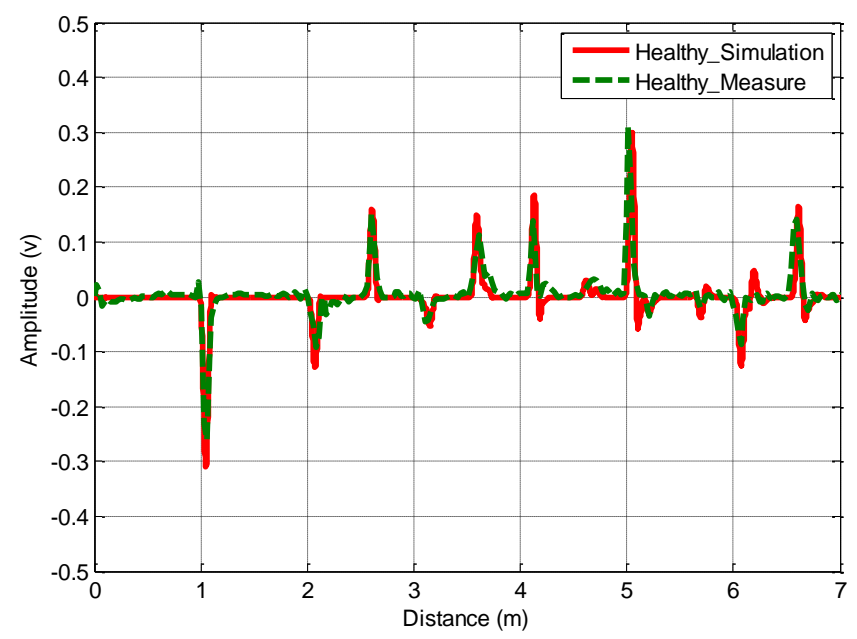

Figure 3: Comparison between the healthy measured and simulated TDR responses of the YY-shaped network.

The faulty study:

In the faulty study two cases are investigated (CASE 1 and CASE 2). The design variables are $L_{1}, L_{2}, L_{3}, L_{4}, L_{5}, R_{1}, R_{2}$, $R_{3}, R_{4}$ and $R_{5}$.

CASE 1: in this first case the test network is affected by one hard fault (short circuit) in $L_{4}$ at $2.4 \mathrm{~m}$ from the origin point as illustrated in Figure 4.

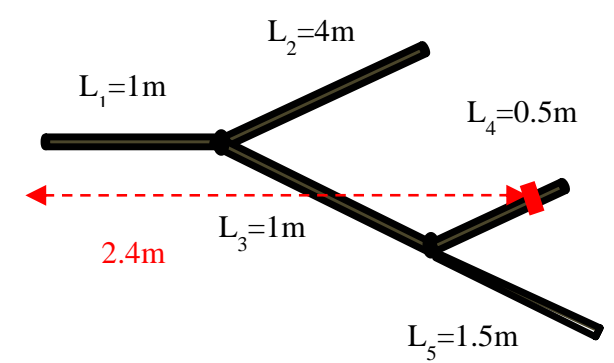

Figure 4: Schematic representation of CASE 1.

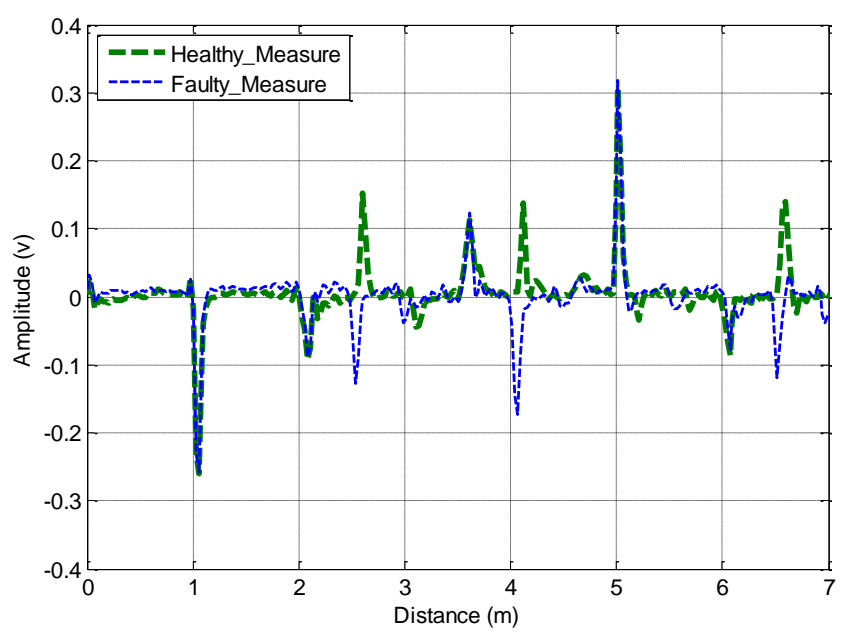

Figure 5: Comparison between the healthy measured and the faulty measured TDR responses for CASE 1 .

Figure 5 illustrates clearly the difference between the healthy and the faulty measured responses of the network considered in CASE 1.

After running the TDR-PSO process (50 iterations), the results obtained are: $L_{1}=1 \mathrm{~m}, L_{2}=4.02 \mathrm{~m}, L_{3}=1.02, L_{4}=0.48$, $L_{5}=1.53, R_{1}=1, R_{2}=1, R_{3}=1 R_{4}=0$ and $R_{5}=1$. The comparison of the obtained results with the known healthy network leads to draw the conclusions summarized in Table 1.

Table I

Fault study for CASE 1.

\begin{tabular}{|l|l|}
\hline Detection & $\begin{array}{l}\text { The tested network is not healthy. It is } \\
\text { affected by one fault. }\end{array}$ \\
\hline Cauterization & $\begin{array}{l}\text { The nature of the fault is a short circuit } \\
\text { one. }\end{array}$ \\
\hline Location & $\begin{array}{l}\text { The fault is located in branch } L_{4} \text { at } 2.48 \\
\text { m from the origin. }\end{array}$ \\
\hline
\end{tabular}

The relative error in locating the fault is $3.33 \%$. Figure shows that the TDR responses of the actual- and 
reconstructed-faulty networks (using the developed approach) match.

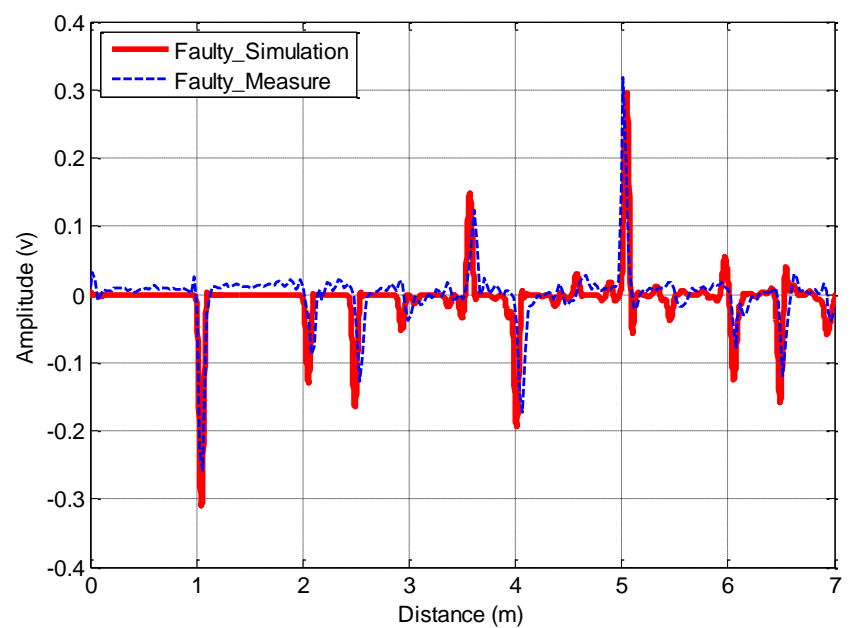

Figure 6: Comparison between the TDR responses measured and reconstructed by the TDR-PSO approach for CASE 1.

CASE 2: This case is illustrated in Figure 7. Here, the test network is assumed to be affected by two hard faults in two different branches: the first fault is an open circuit in $L_{2}$ at $3 \mathrm{~m}$ and the second fault is a short circuit in $L_{4}$ at $2.4 \mathrm{~m}$.

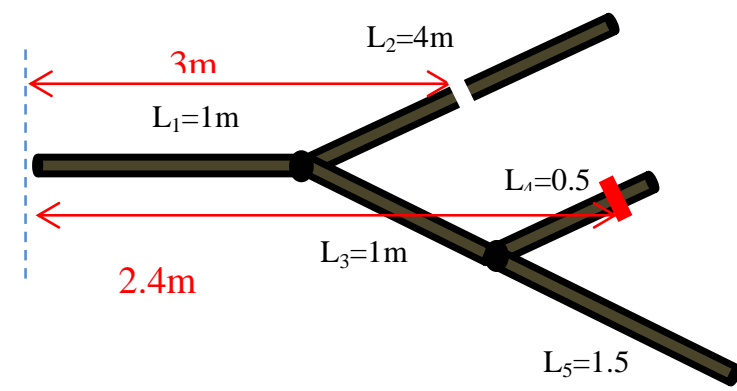

Figure 7: Schematic representation of CASE 2.

After running the TDR-PSO process, the results obtained are: $L_{1}=1 \mathrm{~m}, L_{2}=2.03 \mathrm{~m}, L_{3}=1.02, L_{4}=0.48, L_{5}=1.53, R_{1}=1$, $R_{2}=1, R_{3}=1, R_{4}=0$ and $R_{5}=1$. The comparison of the obtained results with the known healthy network leads to draw the conclusions summarized in Table 2.

\section{Table II}

Faulty study for CASE 2.

\begin{tabular}{|l|l|}
\hline Detection & $\begin{array}{l}\text { The tested network is not healthy. It is } \\
\text { affected by two faults. }\end{array}$ \\
\hline Cauterization & $\begin{array}{l}\text { Fault one is an open circuit while fault two } \\
\text { is a short circuit. }\end{array}$ \\
\hline Location & $\begin{array}{l}\text { The faults are located in } \mathrm{L} 2 \text { at } 3.03 \mathrm{~m} \text { and in } \\
\text { L4 at } 2.48 \mathrm{~m}, \text { respectively. }\end{array}$ \\
\hline
\end{tabular}

The relative errors in locating the first and second faults are: $1 \%$ and $3.33 \%$, respectively. Furthermore, Figure 8 shows the excellent matching between the TDR responses of both: the actual- and reconstructed-faulty networks using the proposed approach.

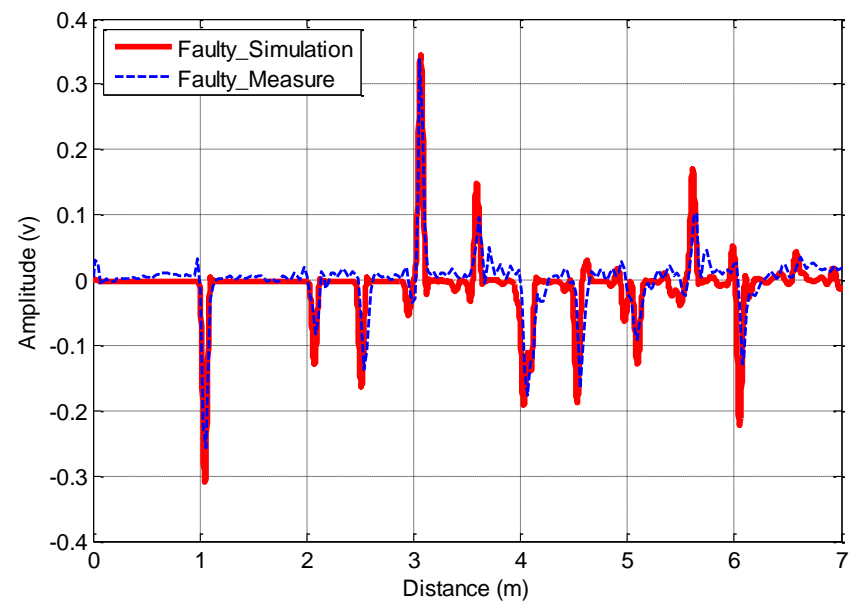

Figure 8: Comparison between the TDR responses measured

and reconstructed by the TDR-PSO approach for CASE 2 .

\section{B. The YYY-shaped network}

Figure 9 shows the Schematic representation of this network composed of seven branches $L_{1}=1 \mathrm{~m}, L_{2}=4 \mathrm{~m}, L_{3}=1 \mathrm{~m}$, $L_{4}=0.5 \mathrm{~m}, L_{5}=1.5 \mathrm{~m}, L_{6}=0.5 \mathrm{~m}$ and $L_{7}=2.5 \mathrm{~m}$ respectively.

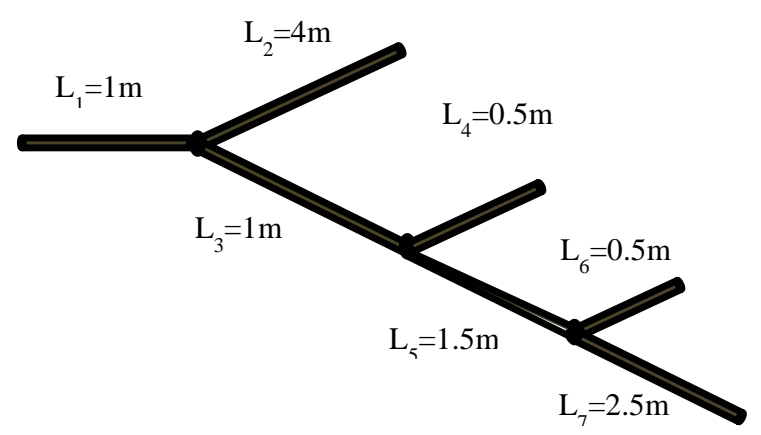

Figure 9: Schematic representation of the healthy YYYshaped network 


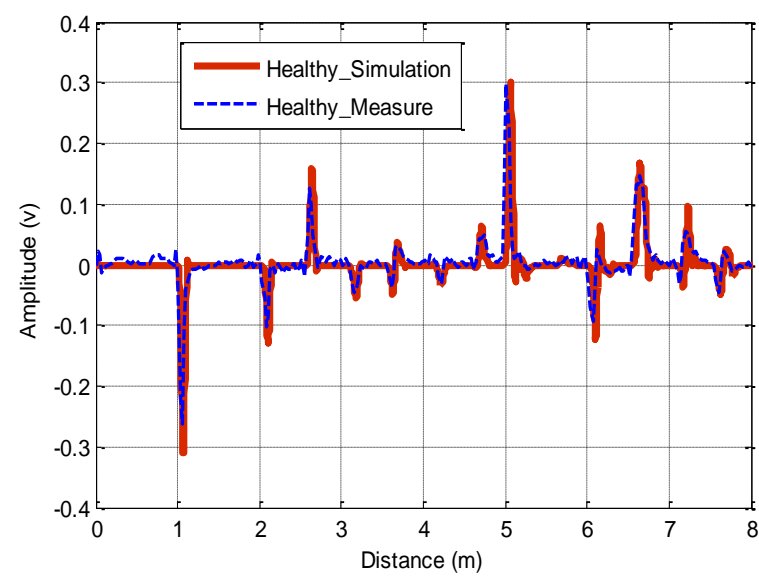

Figure 10: Comparison between the healthy measured and

simulated TDR responses of the YYY-shaped network.

This figure shows that there is a good matching between the measured and simulated results.

\section{The fault study:}

In the fault study two cases are investigated (CASE 1 and CASE 2). The design variables are $L_{1}, L_{2}, L_{3}, L_{4}, L_{5}, L_{6}, L_{7}$, $R_{1}, R_{2}, R_{3}, R_{4}, R_{5}, R_{6}$, and $R_{7}$.

CASE 1: in this first case the test network is affected by two hard faults, short-circuit in $L_{2}$ at $3 \mathrm{~m}$ and an open-circuit in $L_{4}$ at $2.4 \mathrm{~m}$ from the origin point as illustrated in figure 11 .

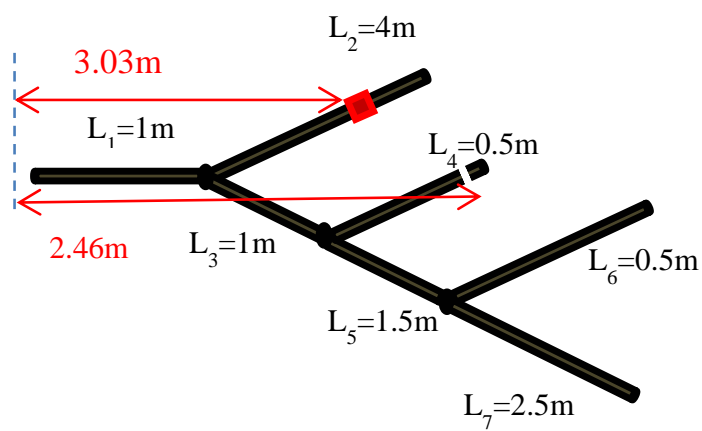

Figure 11: Schematic representation of the case 1

After running the TDR-PSO process (100 iterations), the results obtained are: $L_{1}=1 \mathrm{~m}, L_{2}=2.03 \mathrm{~m}, L_{3}=1.02, L_{4}=0.46$, $L_{5}=1.53, L_{6}=0.53 L_{7}=2.53, R_{1}=1, R_{2}=0, R_{3}=1, R_{4}=1$ and $R_{5}=R_{6}=R_{7}=1$. The comparison of the obtained results with the known healthy network leads to draw the conclusions summarized in Table III.

\section{TABLE III}

Faulty study for CASE 1 .

\begin{tabular}{|l|l|}
\hline Detection & $\begin{array}{l}\text { The tested network is affected by two } \\
\text { hard faults. }\end{array}$ \\
\hline Cauterization & $\begin{array}{l}\text { Fault one is a short circuit while fault } \\
\text { two is an open circuit. }\end{array}$ \\
\hline Location & $\begin{array}{l}\text { The faults are located in L2 at } 3.03 \mathrm{~m} \\
\text { and in L4 at } 2.46 \mathrm{~m}, \text { respectively. }\end{array}$ \\
\hline
\end{tabular}

Figure 12 shows the excellent matching between the TDR responses of both: the actual- and reconstructed-faulty networks using the proposed approach.

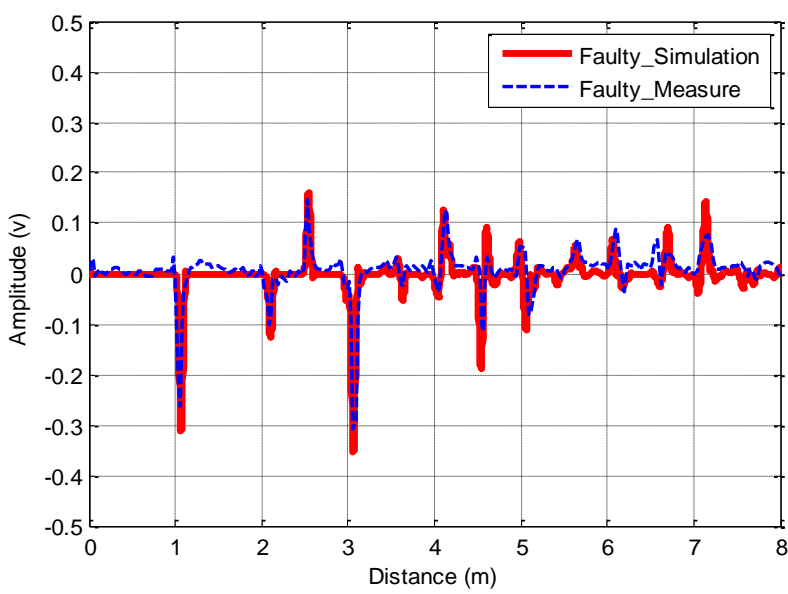

Figure 12: Comparison between the TDR responses measured and reconstructed by the TDR-PSO approach for

CASE 1 .

CASE 2: in this case the test network is affected by three hard faults; short-circuit in $L_{2}$ at $1.4 \mathrm{~m}$, another in $L_{4}$ at $2.4 \mathrm{~m}$ and an open-circuit in $L_{7}$ at $5.5 \mathrm{~m}$ from the origin point as illustrated in figure 13.

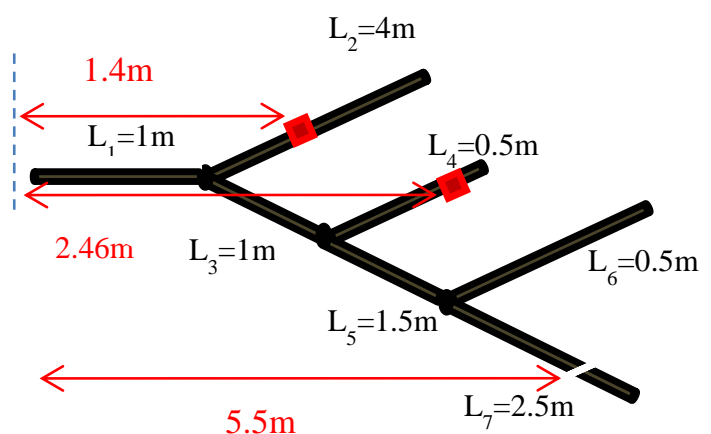

Figure 13: Schematic representation of the case 2. 
After running the TDR-PSO process (100 iterations), the results obtained are: $\mathrm{L} 1=1 \mathrm{~m}, \mathrm{~L} 2=0.43 \mathrm{~m}, \mathrm{~L} 3=1.02 \mathrm{~m}$, $\mathrm{L} 4=0.46 \mathrm{~m}, \mathrm{~L} 5=1.53 \mathrm{~m}, \mathrm{~L} 6=0.5 \mathrm{~m}, \mathrm{~L} 7=2 \mathrm{~m}, \mathrm{R} 1=1, \mathrm{R} 2=0$, $\mathrm{R} 3=1, \mathrm{R} 4=0$ and $\mathrm{R} 5=\mathrm{R} 6=\mathrm{R} 7=1$. The comparison of the obtained results with the known healthy network leads to draw the conclusions summarized in Table IV.

\section{TABLE IV}

Faulty study for CASE 2.

\begin{tabular}{|l|l|}
\hline Detection & $\begin{array}{l}\text { The tested network is affected by three } \\
\text { hard faults. }\end{array}$ \\
\hline $\begin{array}{l}\text { Cauteriza- } \\
\text { tion }\end{array}$ & $\begin{array}{l}\text { Fault one and two are short circuits while } \\
\text { fault three is an open circuit. }\end{array}$ \\
\hline Location & $\begin{array}{l}\text { The faults are located in L2 at } 1.4 \mathrm{~m} \text { and in } \\
\text { L4 at } 2.46 \mathrm{~m} \text {, and in L7 at } 5.5 \mathrm{~m} \text { respec- } \\
\text { tively. }\end{array}$ \\
\hline
\end{tabular}

Figure 14 shows the excellent matching between the TDR responses of both: the actual- and reconstructed-faulty networks using the proposed approach.

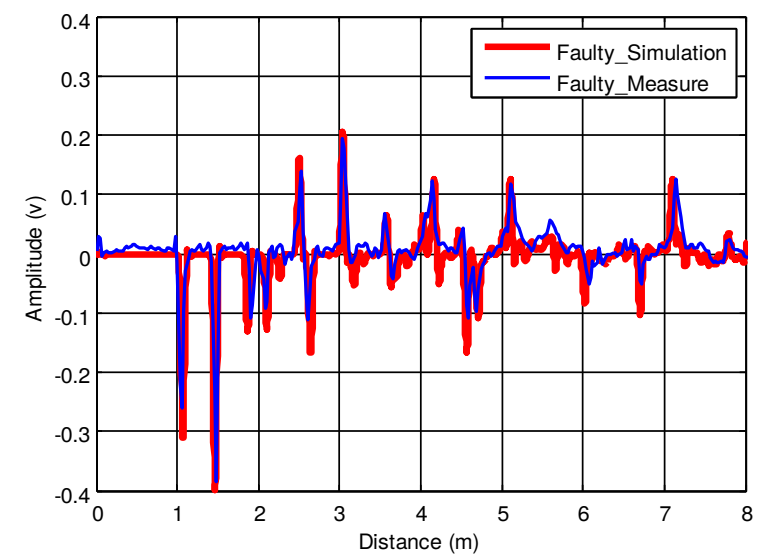

Figure 14: Comparison between the TDR responses measured and reconstructed by the TDR-PSO approach for CASE 2.

\section{CONCLUSION}

In this article, a novel methodology based on TDR and PSO for the Non-Destructive Diagnosis of cabling networks is proposed, the physical informations about the network are deduced by processing the reflectometry response and solving the inverse problem by the PSO. The proposed approach has been successfully tested on several cases and for different configurations such as the YY and the YYYshaped networks. The comparisons of the proposed TDRPSO approach results with measurements reveal that this approach has a high potential and it is very effective for cabling network diagnosis.

\section{REFERENCES}

[1]. Furse, Cynthia, Lo, Chet, "Reflectometry for Locating Wiring Faults," IEEE Trans. Electromagnetic Compatibility. February, 2005.

[2]. M. K. Smail, T. Hacib, L. Pichon, and F. Loete, "Detection and location of defects in wiring networks using time-domain reflectometry and neural networks," IEEE Trans. Magn, vol. 47, no. 5, may 2011.

[3]. Layane Abboud, Andrea Cozza, and Lionel Pichon, "A MatchedPulse Approach for Soft-Fault Detection in Complex Wire Networks," IEEE Trans. Instrumentation and Measurement, vol. 61, no. 6, June 2012.

[4]. H. R. E. H. Bouchekara, M. K. Smail, and G. Dahman"Diagnosis of Multi-Fault Wiring NetworkUsing Time-Domain Reflectometry and Electromagnetism-Like Mechanism," Electromagnetics, 33:2, 131143.

[5]. C R Paul, Analysis of Multiconductor transmission lines, New York Wiley 1994.Halliday, D. and Resnick, R., 1962, Physics, Part II, 2nd ed., John Wiley \& Sons, New York.

[6]. Halliday, D. and Resnick, R., 1962, Physics, Part II, 2nd ed., John Wiley \& Sons, New York.

[7]. Kennedy, J. Eberhart, R. C. Particle swarm optimization. Proceedings IEEE international conference on neural networks, vol. 7 (1995), pp 1942- 1948.

[8]. R. Rajendra, D. K. Pratihar, Particle Swarm Optimization Algorithm vs Genetic Algorithm to Develop Integrated Scheme for Obtaining Optimal Mechanical Structure and Adaptive Controller of a Robot Open Access, Intelligent Control and Automation,vol.2 (2011).

[9]. M. El-Abd, Cooperative models of particle swarm optimizers. University of Waterloo, Canada, ProQuest Dissertations and Theses, 2008.

[10]. Robinson, J. and Y. Rahmat-Samii, Particle swarm optimization in electromagnetics, IEEE Transactions on Antennas and Propagation, vol. 52 (2004), pp. 397-407. 